
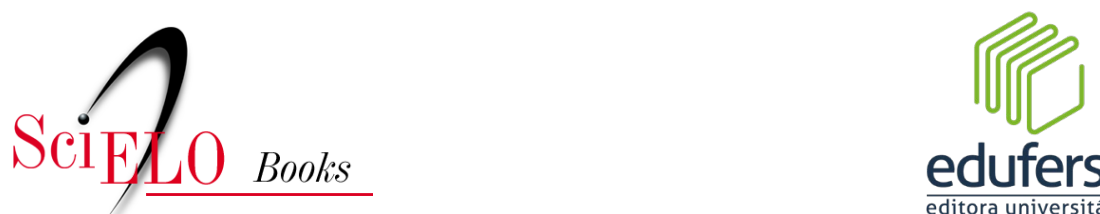
edufersa

\title{
Capítulo 4 - Perfil empreendedor: comparativo entre gêneros e orientação religiosa
}

\author{
Paulo Alexandre da Rocha Morais \\ Alexandre José de Oliveira \\ Alexandre dos Santos Barros
}

\section{SciELO Books / SciELO Livros / SciELO Libros}

MORAIS, P. A. R., OLIVEIRA, A. J., and BARROS, A. S. Perfil empreendedor: comparativo entre gêneros e orientação religiosa. In: OLIVEIRA, A. M. B., ed. Empreendedorismo: registros de estudos teórico-empíricos no semiárido [online]. Mossoró: EdUFERSA, 2018, pp. 123-150. ISBN: 978-85-5757-090-0. https://doi.org/10.7476/9786587108667.0006.

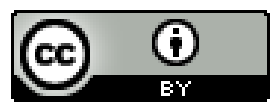

All the contents of this work, except where otherwise noted, is licensed under a Creative Commons Attribution 4.0 International license.

Todo o conteúdo deste trabalho, exceto quando houver ressalva, é publicado sob a licença Creative Commons Atribição 4.0.

Todo el contenido de esta obra, excepto donde se indique lo contrario, está bajo licencia de la licencia Creative Commons Reconocimento 4.0. 


\title{
PERFIL EMPREENDEDOR: COMPARATIVO ENTRE GÊNEROS E ORIENTAÇÃO RELIGIOSA
}

\author{
Paulo Alexandre da Rocha Morais \\ Alexandre José de Oliveira \\ Alexandre dos Santos Barros
}

\subsection{Introdução}

Em uma perspectiva macro, tem sido consenso, na literatura sobre o tema, a importância do empreendedorismo para o desenvolvimento econômico de um país (VIEIRA; JACINTO, 2013). O empreendedorismo, nessas três últimas décadas, surge como uma alternativa de carreira para muitos. Isso se deve a alguns fatores, como: a reestruturação produtiva necessária, para atender aos novos padrões de concorrência internacional; a redução dos postos de trabalho na forma de emprego formal e as novas oportunidades de trabalho, além da abertura de mercado, geradas com a globalização e o avanço da tecnologia (SERAFIM; FEUERSCHÜTTE, 2015).

No entanto, além dos fatores sociais e macroambientais, como os econômicos, políticos e tecnológicos, outros fatores individuais também contribuem para o processo de empreender (BARON; SHANE, 2007). Dessa forma, em uma perspectiva micro, conhecer as características individuais do agente desse processo, o empreendedor, também é importante. De acordo com Vieira e Jacinto (2013), o estudo do empreendedorismo, em uma perspectiva micro, tem sido um desafio para a literatura corrente, tendo em vista que conhecer as características do empreendedor, suas atitudes e comportamentos, requer adentrar em seus valores e princípios pessoais. 
Ferreira e Nogueira (2013), com base em um levantamento feito nos principais periódicos de Administração e de eventos científicos no Brasil, salientam que ainda é inexpressiva a discussão sobre o empreendedorismo. Com isso em mente, advogam a necessidade de novos estudos que tragam novos enfoques ao tema. Mais especificamente, Inácio Júnior et al. (2014), após análise da literatura brasileira sobre o tema nos últimos quatro anos, apontam para a necessidade de mais estudos direcionados para avaliar o empreendedorismo em níveis individual e institucional.

Em complemento, Martes (2010), fundamentado em Weber e Schumpeter, defende que o empreendedor, unidade básica de análise do empreendedorismo, na condição de um indivíduo, deve ser concebido como um ser concreto, inserido em instituições sociais que moldam seus valores e, por conseguinte, suas ações e intenções. Com base nesses argumentos, este estudo se propõe contribuir com a discussão sobre o tema e investigar a relação do empreendedorismo com duas variáveis, que são, ao mesmo tempo, individuais e institucionais: gênero e religião. Assim, são objetivos da pesquisa: verificar se a diferença entre as médias do perfil empreendedor de homens e mulheres e de católicos e protestantes é significativa.

Nos tópicos seguintes, uma breve explanação sobre a relação do empreendedorismo com essas duas variáveis, encontrada na literatura, seguida dos procedimentos metodológicos utilizados para alcançar os objetivos de pesquisa, que convergem para a apresentação dos resultados encontrados. Por fim, as considerações finais sobre as contribuições e limitações deste trabalho, bem como as sugestões para novos estudos.

\subsection{Empreendedorismo e gênero}

Os estudos que abordam a relação entre empreendedorismo e gênero, em geral, fundamentam-se em duas teorias: feminista liberal e/ou 
feminista social (FISCHER; REUBER; DYKE, 1993). A teoria feminista liberal sugere que as mulheres estão em desvantagem em relação aos homens, devido à discriminação ostensiva e/ou a fatores sistêmicos que as privam de acesso aos recursos vitais, como educação e experiência empresarial. A teoria feminista social, por sua vez, sugere que, devido a diferenças na socialização precoce e contínua, homens e mulheres diferem inerentemente. No entanto, também sugere que isso não significa que as mulheres sejam inferiores aos homens e, sim, que homens e mulheres podem desenvolver características diferentes, mas igualmente eficazes para empreender.

Em linha com essas duas correntes teóricas, Ferreira e Nogueira (2013), em uma análise qualitativa realizada com mulheres empreendedoras, sugerem que a subjetividade dessas mulheres é constituída de um conjunto de fatores que incluem suas trajetórias de vida e seu contexto atual e cultural. Sendo assim, a forma como empreendem sofre influência de suas vivências concretas, de seu contexto sócio histórico.

Em concordância, a luta por igualdade de gêneros e o aumento e a necessidade de meios de subsistência formal e informal advindos da industrialização são catalizadores do empreendedorismo feminino. Contudo, o ônus de ser mulher, como uma condição biológica, ainda reina nos discursos daquelas que empreendem. Pelo exposto, ao empreenderem $\mathrm{m}_{2}$ essas mulheres estão quebrando paradigmas sociais que ainda permeiam o século XXI (FERREIRA; NOGUEIRA, 2013). Assim, de acordo com Jonathan (2011), é por meio dessas ações empreendedoras que as mulheres vêm promovendo espaços de transformação de si mesmas e do contexto social, econômico e cultural no qual estão inseridas.

Peñaloza, Diógenes e Sousa (2008) lembram que a inserção no mercado de trabalho e o acesso do público feminino ao ensino superior vêm contribuindo para modificar o papel das mulheres na sociedade. Nesse sentido, especificamente em relação ao Brasil, o Relatório Executivo 
do Global Entrepreneurship Monitor (GEM, 2015a), que traz os dados do país em 2014, notifica que o papel das mulheres em atividades empreendedoras tem sido expressivo e vem aumentando nos últimos anos. Percentualmente, do total de empreendedores iniciais e estabelecidos, 48,3\% são mulheres e 51,7\% são homens. Esses números aumentam quando se consideram apenas os empreendedores iniciais, com menos de quatro anos, dos quais $51,2 \%$ são mulheres e 48,8 são homens.

No entanto, em nível global, na grande maioria dos 72 países que participaram na pesquisa de 2014, a predominância ainda é de empreendedores do sexo masculino. Segundo a análise apresentada no 2014 Global Report (GEM, 2015b), essa predominância dá-se em virtude de uma mescla de aspectos culturais, sociais e econômicos e não somente de características individuais, como oportunidades e capacidades percebidas.

Vale, Serafim e Teodósio (2011) e Powell e Eddleston (2013) corroboram com essa análise ao afirmarem que, historicamente, homens e mulheres estiveram imersos em redes sociais diferentes. Devido à falta de acesso a recursos vitais - humanos, sociais e financeiros - as mulheres desenvolvem uma sinergia maior entre trabalho-família e sua rede de contatos pessoais. Isso, por sua vez, condiciona ou influencia a forma como conduzem seus empreendimentos, mas não a sua intenção ou o seu potencial de empreender. Simultaneamente, em um estudo inédito realizado nos Países Baixos da Europa com mais de 2000 participantes, Van der Loos et al. (2013) não encontraram evidências empíricas que comprovem a relação entre testosterona e comportamento empreendedor nos homens. Essas evidências sugerem que a constituição biológica, por si só, não define o perfil empreendedor de um indivíduo.

Jonathan (2011), com base em uma análise qualitativa com 149 empreendedoras brasileiras, também confirma a análise do GEM (2015b). Essa análise consistiu em compreender as motivações para empreender, as consequências e dificuldades enfrentadas, bem como 
as estratégias utilizadas para enfrentar as demandas vinculadas à multiplicidade de papéis dessas mulheres de forma particular. Dentre as principais motivações ou intenções para empreender dessas mulheres, estão a autorrealização e a independência financeira. Isso mostra que, de forma proativa, as empreendedoras buscam manifestar o seu potencial.

As análises quantitativas de dois estudos interculturais apoiam as afirmações anteriores. Muller e Dato-on (2013) realizaram um estudo envolvendo a cultura americana e a espanhola, com o intuito de compreender a relação entre autoeficácia empresarial e motivação empreendedora e gênero. Os resultados desse estudo indicam que o contexto cultural afeta essa relação. Enquanto que, na cultura Americana, não há diferenças entre homens e mulheres em relação ao nível de autoeficácia empresarial e motivação empreendedora, na cultura Espanhola, o estereótipo tradicional de gênero ainda persiste. Em complemento, Shinnar, Giacomin e Janssen (2012), com uma amostra de 761 estudantes chineses, belgas e americanos de cursos diversos, evidenciam que a diferença entre gêneros quanto à percepção de barreiras e à intenção para empreender é moderada pela cultura desses países.

Pelo exposto, estabelece-se, como primeira hipótese, que há diferenças significativas entre o perfil empreendedor de homens e mulheres.

\subsection{Empreendedorismo e religião}

De acordo com Vieira e Jacinto (2013), historicamente, as religiões exercem um importante papel na sociedade, pois servem de doutrina e provêm valores e princípios morais aos seus adeptos. Esses valores e princípios morais são constituintes nas tomadas de decisão quanto à ação de empreender. Muitos dos estudos que evidenciam a relação entre empreendedorismo e religião justificam-se pela mesma suposição (GRANOVETTER, 2007; MARTES; RODRIGUEZ, 2004; SERAFIM; MARTES; RODRIGUEZ, 2012; SERAFIM; FEUERSCHÜTTE, 2015). 
A obra máxima de Weber (2004), que atrela o capitalismo à ética protestante, é referência indispensável para estudar essa relação. Nesse ensaio histórico e sociológico, Weber disserta sobre a influência da doutrina protestante, de uma prática de vida racional e metódica por ganhos econômicos, na formação do conjunto de crenças, hábitos e traços comportamentais de seus adeptos. Essa prática religiosa, do ponto de vista econômico, pode estar associada ao empreendedorismo e molda o agente desse processo, o empreendedor (SERAFIM; FEUERSCHÜTTE, 2015).

Martes e Rodriguez (2004) foram uns dos primeiros a chamar a atenção de pesquisadores brasileiros para a importância dos efeitos da afiliação a organizações religiosas nas iniciativas empreendedoras. Segundo os autores, as diferenças na estrutura institucional dessas organizações, suas práticas, formas de financiamento, e o conteúdo do discurso empregado por seus líderes religiosos são fatores que podem impactar positiva ou negativamente no processo de empreender.

Isso acontece devido ao fato de que essas instituições, independentemente de suas doutrinas religiosas, podem oferecer um ambiente seguro, de contatos sociais com maiores níveis de confiança e solidariedade e atrair adeptos que compartilham de crenças, valores e motivações pessoais. De acordo com Serafim, Martes e Rodriguez (2012), embora o senso de pertencimento possa ser o mesmo, o que muda é a forma como seus adeptos, imbricados no sistema de valores de sua instituição religiosa, concebem o sucesso econômico e se articulam como rede social.

Com isso em mente, Serafim e Feuerschütte (2015) sugerem que as relações interpessoais e os aspectos culturais que permeiam as instituições religiosas moldam a ação empreendedora, tendo em vista que as relações interpessoais e os aspectos culturais podem ser fontes de recursos financeiros e/ou de informação, além de oferecerem aceitação e identidade grupal. Munidos do mesmo pensamento, Sabah, Carsrud 
e Kocak (2014) concebem as instituições religiosas como elos entre as organizações empresariais com interesses semelhantes. Esses elos, também conhecidos como redes de relacionamentos, são influenciados por valores étnicos e culturais e podem ser uma fonte de vantagem para essas organizações.

Nesse sentido, Silver e O’Neill (2014) argumentam, fundamentados na filosofia do dinheiro de Georg Simmel, que "o caráter transcendente da vida" permeia as interações monetárias mundanas. Especificamente, para esses autores, as formas religiosas de experiência chave, como fé, unidade e individualidade, existem em troca monetária e apontam para uma maneira distintiva simmeliana para entender a relação entre religião e economia.

A relação entre religião e economia já havia sido sugerida por Carswell e Rolland (2007) e Audretsch, Bönte e Tamvada (2007). Carswell e Rolland (2007) reconhecem a filiação religiosa como um motor potencialmente importante para o crescimento econômico, depois de um estudo realizado na Nova Zelândia, com 2.000 indivíduos. As evidências desse estudo indicam que as religiões não cristãs podem ser mais empreendedoras que as cristãs. Por sua vez, com base em um conjunto de dados com quase 90.000 trabalhadores na Índia, Audretsch, Bönte e Tamvada (2007) concluem que a religião influencia o empreendedorismo e, por conseguinte, o desenvolvimento econômico. De forma particular, no contexto indiano, os dados mostram que o Islamismo e o Cristianismo favorecem e o Hinduísmo inibe o comportamento empreendedor.

Em outro momento, os mesmos autores, Audretsch, Bönte e Tamvada (2013), motivados pela perspectiva da teoria institucional, realizaram outra pesquisa e seguiram com o argumento de que elementos da religião devem ser explicitamente considerados para compreender o que influencia o empreendedorismo. Eles advogam que, ainda que o ambiente regulatório das pessoas de diferentes religiões seja o mesmo, as dimensões normativas e cognitivas diferem significativamente 
entre as religiões e dão origem a perfis institucionais que são ou não propícios ao autoemprego. Assim, enquanto os perfis institucionais do Hinduísmo e do Budismo o restringem, os perfis institucionais do Islamismo e do Jainismo incentivam suas atividades. Na mesma linha, Hoogendoorn, Rietveld e van Stel (2014), depois de uma análise empírica, em um conjunto de dados de painel de 30 países da OCDE, defendem a religiosidade institucionalizada como um fator determinante sobre a taxa de propriedade de negócios.

Em contraponto, Griebel, Park e Neubert (2014), com base em uma pesquisa com cristãos americanos, sugerem que é a natureza individualizada da religião que influencia o empreendedorismo, tendo em vista que o comportamento empreendedor é moldado por uma necessidade de seus agentes de reinterpretar o seu trabalho em termos religiosos, diminuindo a tensão entre fé e trabalho. Dessa forma, os indivíduos empreendedores criam um ambiente de trabalho com base em valores que manifestam a sua fé, tais como família, bom caráter e ajuda aos outros, e estabelecem uma relação autônoma e não institucional com a religião. Em adição, Vieira e Jacinto (2013) ressaltam que as principais teorias levam em conta o empreendedor como um agente econômico diferente dos demais, sendo movido por valores e motivações, não só sujeitas ao ambiente, mas também às características próprias de cada indivíduo.

Em relação especificamente às duas principais religiões de denominação cristã, Catolicismo e Protestantismo, três estudos se destacam (SERAFIM; MARTES; RODRIGUEZ, 2012; SERAFIM, 2013; VIEIRA; JACINTO, 2013; GALDEANO, 2014). Nesses estudos, todos de natureza qualitativa, os resultados encontrados convergem para a mesma afirmação: as organizações religiosas protestantes são mais ativas no apoio ao empreendedorismo que as organizações religiosas católicas. Serafim e Feuerschütte (2015) justificam esses resultados, concluindo que o apoio ao empreendedorismo por parte do protestantismo é um 
fim em si mesmo, enquanto que, para o catolicismo, é um meio para um projeto econômico mais amplo.

Portanto, constitui-se, como segunda hipótese, a de que há diferenças significativas entre o perfil empreendedor de católicos e protestantes.

\subsection{Procedimentos metodológicos}

A mensuração do perfil empreendedor deu-se por meio de uma escala elaborada e validada por Santos (2008) em seu doutorado. A escala possui 49 itens, que são afirmações sobre características empreendedoras e mensuram, em conjunto, o perfil empreendedor. É organizada em duas partes, que constituem os fatores intenção de empreender e potencial empreendedor. Os quatro primeiros itens compõem a primeira parte e buscam prever a intenção de empreender, o desejo de possuir o próprio negócio. Os 45 itens restantes formam a segunda parte e examinam o potencial empreendedor, que se refere às características individuais necessárias em um processo empreendedor. Esse fator está dividido em nove subfatores: oportunidade, persistência, eficiência, informações, planejamento, metas, controle, persuasão e rede de relações. Para cada item, o respondente era solicitado a valorar, com uma nota de 0 a 10, seu grau de afinidade com a situação exposta na questão (SANTOS, 2008; SANTOS; CAETANO; CURRAL, 2010; MORAIS, 2013). Na sequência, uma breve descrição dos subfatores que compõem o fator potencial empreendedor.

O subfator oportunidade está relacionado à capacidade de identificar oportunidades. O subfator persistência, por sua vez, diz respeito à capacidade de se manter firme na busca do sucesso, sendo persistente em seus objetivos e metas, superando todos os obstáculos pelo caminho para alcançar o sucesso. Enquanto que o subfator eficiência trata da capacidade de desenvolver e utilizar procedimentos que assegurem que a tarefa seja realizada ao menor custo possível. O subfator 
informações refere-se à disponibilidade em aprender coisas novas e demonstrar avidez em obter mais conhecimentos. Em adição, o subfator planejamento está relacionado à capacidade de planejar as atividades a partir dos objetivos definidos, de forma detalhada. Outro subfator é meta, que foca na capacidade de mostrar determinação, senso de direção. $\mathrm{O}$ subfator controle faz referência à capacidade de acompanhar a execução dos planos elaborados, mantendo registros e utilizando-os para o processo de tomada de decisão. Já o subfator persuasão trata da capacidade de convencer e inspirar pessoas, liderar e estimular a equipe por meio de palavras e ações. Por fim, o subfator rede de relações refere-se à habilidade de estabelecer contatos com todos aqueles que, direta ou indiretamente, possam ser úteis para o alcance de seus objetivos, montando, assim, uma boa rede de relacionamento.

De acordo com Rocha e Freitas (2014), uma escala que mensura o perfil empreendedor e não apenas a intenção de empreender ameniza as limitações dessa última variável. Esse foi o principal motivo da escolha dessa escala, a inclusão e o detalhamento do fator potencial empreendedor. Dessa forma, ao avaliar a intenção de empreender e o potencial empreender em conjunto, parte-se da premissa do empreendedor, como um indivíduo, com características únicas, mas, ao mesmo tempo, um ser concreto, inserido em um contexto histórico, político e social. Além disso, essa é uma escala desenvolvida e validada no e para o contexto brasileiro.

Para possibilitar a caracterização da amostra e posterior análise das variáveis, adicionou-se a escala de Santos (2008), que contém questões referentes à identificação do gênero e da religião dos respondentes. Os respondentes foram os bacharelandos em ciências e tecnologia de uma Instituição Federal de Ensino Superior (IFES), localizada no Nordeste do Brasil. Para compor a amostra, elegeram-se os 195 discentes, regularmente matriculados no semestre 2013.1 na disciplina Administração e Empreendedorismo. Essa disciplina é obrigatória 
para todos os discentes desse curso e é ofertada no último ano. 141, dos 195 discentes matriculados na referida disciplina nos três turnos, responderam em sala de aula ao instrumento de coleta. Dessa forma, em relação à amostra total, o índice de respostas foi de 72,31\%.

Para a tabulação dos dados obtidos, foi iniciada a estratégia de análise, com o software IBM SPSS Statistics, v. 24.0; onde foram realizados a análise de confiabilidade da escala utilizada, a estatística descritiva e o teste de hipótese.

\subsection{Apresentação e análise dos dados}

A confiabilidade da escala utilizada para mensurar o perfil empreendedor foi avaliada através do coeficiente de alfa de Cronbach $(\alpha)$, que é usado para medir a correlação entre as respostas do questionário por meio das respostas dadas pelos respondentes. $\mathrm{O}$ alfa pode variar de acordo com o tamanho da população à qual foi aplicado, aumentando quando aumentam as intercorrelações entre os itens que formam a escala. Por isso, quanto maior o número de itens, maior a variância (ALMEIDA; SANTOS; COSTA, 2010). Segundo Freitas e Rodrigues (2005), quando uma escala apresenta um valor de alfa entre 0,750 a 0,900 , tem confiabilidade alta; e maior que 0,900 , tem confiabilidade muito alta. Na Tabela 8, os valores apresentados para cada um dos fatores e subfatores revelam uma confiabilidade de alta muito alta.

Em relação à amostra, 66,4\% dos respondentes são do sexo masculino e 33,6\% do sexo feminino. Quanto à religião dos respondentes, $62,3 \%$ se consideram católicos, $21,0 \%$ protestantes e 16,7 responderam outras opções, sendo, dessas, 3,6\% espíritas, 2,2\% ateus e 10,9\% outras não especificadas. Para efeito deste trabalho, só foram considerados os respondentes católicos e protestantes. 
Tabela 8 - Análise de confiabilidade do instrumento e de seus fatores

\begin{tabular}{ccc}
\hline Fatores & $\alpha$ & $\mathbf{n}^{\mathbf{o}}$ itens \\
\hline Intenção de empreender & 0,959 & 4 \\
Oportunidade & 0,807 & 5 \\
Persistência & 0,848 & 6 \\
Eficiência & 0,883 & 3 \\
Informações & 0,933 & 5 \\
Planejamento & 0,930 & 4 \\
Metas & 0,978 & 7 \\
Controle & 0,973 & 5 \\
Persuasão & 0,988 & 6 \\
Rede de relações & 0,985 & 4 \\
Potencial Empreendedor & 0,982 & 45 \\
\hline
\end{tabular}

Fonte: Dados da pesquisa (2013).

\subsubsection{Teste de hipótese}

O teste t para amostras independentes foi empregado para atender ao objetivo da pesquisa. Esse teste permite contrastar hipóteses referentes à diferença entre as médias de dois grupos distintos de sujeitos. Para efeito deste trabalho, a amostra foi trabalhada separadamente em grupos, primeiro por gênero ( 1 - sexo masculino, 2 - sexo feminino) e depois por religião ( 1 - católicos, 2 - protestantes).

O teste té uma tipificação da diferença entre as duas médias amostrais. Essa tipificação é obtida pela fórmula:

$$
T=(\bar{\Upsilon} 1-\bar{\Upsilon} 2)-(\mu 1-\mu 2) / \sigma \bar{\Upsilon} 1-\bar{\Upsilon} 2
$$

onde $\mu 1$ e $\mu 2$ consiste nas médias dos grupos; $\mathrm{n} 1$ e $\mathrm{n} 2$, nos tamanhos de amostra dos grupos; $\bar{\Upsilon} 1$ e $\bar{\Upsilon} 2$, nas médias amostrais dos grupos; e, $\sigma \bar{\Upsilon} 1$ - $\bar{\Upsilon} 2$, no erro padrão da diferença entre as médias. 
O estatístico do teste $\mathrm{t}(\mathrm{t})$ tem duas formas diferentes de estimar o erro padrão da diferença: $\sigma \bar{\Upsilon} 1-\bar{\Upsilon} 2$, assumindo que as variâncias populacionais são iguais ou não, por meio do teste de Levene. Dessa forma, se a probabilidade (p-valor) associada ao estatístico de Levene (Z) for maior que 0,05 , infere-se que as variâncias são iguais; em caso contrário, se essa probabilidade for menor que 0,05 , deve-se rejeitar a hipótese de igualdade de variâncias (MERINO; DÍAZ, 2005).

Esse método, embora tradicionalmente empregado na maioria dos pacotes estatísticos, requer que importante pressuposto seja garantido: as variáveis de interesse sejam distribuídas normalmente (ou distribuição gaussiana). Com essa violação de pressuposto, os estatísticos t calculados, assim como os intervalos de confiança, não são válidos e, portanto, qualquer inferência sobre as diferenças pode estar comprometida. Na existência de tais riscos, uma importante metodologia vem ganhando amplo destaque nos modelos estatísticos: o método de bootstrap.

O método de bootstrap consiste em uma abordagem não paramétrica de inferência estatística, que substitui os métodos tradicionais, cujos pressupostos clássicos de distribuição das variáveis não podem ser relaxados. Esse método permite estimar uma distribuição amostral de uma estatística de interesse sem as devidas suposições tradicionais da forma funcional da população ou das definições explícitas da própria distribuição amostral (FOX, 2008).

Assim, os métodos usuais de inferência dependem de uma teoria assintótica que conduz a distribuição dos dados diretamente para formas funcionais pré-estabelecidas, como a exemplo da distribuição normal (CAMERON; TRIVEDI, 2005). A ideia básica por trás do método consiste em definir sucessivas subamostras ou reamostras a partir da amostra original, denominadas de replicações amostrais, às quais serão estimadas as estatísticas de interesse: 


$$
\operatorname{Var}^{*}(\hat{\theta})=\frac{1}{B-1} \sum_{i=1}^{B}\left(\hat{\theta}_{i}^{*}-\overline{\hat{\theta}}^{*}\right)^{2}, \overline{\hat{\theta}}^{*}=\frac{1}{B} \sum_{i=1}^{B} \hat{\theta}_{i}^{*}
$$

onde $\widehat{\theta}_{i}^{*}$ consiste no estimador calculado a partir da $i$-ésima reamostra e $\overline{\hat{\theta}}^{*}$, na média dos valores reamostrados. A partir da variância calculada, estima-se o desvio-padrão e, em seguida, constroem-se os intervalos de confiança para inferir sobre a significância da estatística de teste.

Cameron e Trivedi (2005) adotam uma regra simples para definição do número 'adequado' de replicações,

$$
\mathrm{n}=\mathrm{\alpha}(\mathrm{B}+1)
$$

onde ' $n$ ' representa o tamanho da amostra e ' $\alpha$ ', o nível de significância a ser usado na construção do intervalo de confiança. Neste estudo, foi considerado um nível de significância máximo de 5\% (). Assim, o número ideal de replicações consistiu em 2819 reamostras. Quanto maior o número de reamostras, mais consistente será a estimativa de erro-padrão e, consequentemente, a confiança nos testes de hipótese.

As Tabelas 9 e 10 apresentam os resultados da análise das diferenças entre as médias dos grupos por gênero ( 1 - sexo masculino e 2 - sexo feminino) e por religião ( 1 - católicos e 2 - protestantes), respetivamente. Uma breve explanação desses resultados segue nos parágrafos seguintes.

Em relação à variável gênero, observam-se, nos dados da Tabela 9 , que a média dos homens em relação ao fator intenção de empreender foi maior que a média das mulheres. No entanto, a média das mulheres em todos os subfatores referentes ao fator potencial empreendedor foi maior que a média dos homens.

Importante salientar que a intenção de empreender está relacionada às pressões e padrões sociais de como comportar-se, bem como à crença de um indivíduo de que é capaz de comportar-se de determinada forma. 
O potencial empreendedor, por sua vez, envolve traços ou características de personalidade latentes, que podem ou não vir a se manifestar, a depender das experiências de vida desse indivíduo (SANTOS, 2008). Portanto, uma justificativa para esses resultados preliminares é que os homens estão mais propensos a empreender que as mulheres, devido à herança histórica e cultural do papel imbuído ao gênero masculino. Esse mesmo resultado foi encontrado no estudo de Peñaloza, Diógenes e Sousa (2008), realizado no Brasil, com graduandos em Administração em outra universidade nordestina. Por outro lado, as mulheres são mais capazes de desenvolver atividades empreendedoras que os homens, devido às características inerentes ao universo feminino.

Contudo, quando as diferenças entre as médias foram analisadas estatisticamente, apenas aquelas referentes aos subfatores planejamento e controle e ao fator potencial empreendedor foram consideradas significativas, considerando o nível máximo de $10 \%$. Estatisticamente, a diferença entre a média das mulheres em relação à média dos homens para o subfator planejamento foi significativa, ao nível de $1 \%$, nos dois métodos estimados, tradicional e bootstrap, com 2819 replicações. Já para o subfator controle, a significância sofreu alteração de um método para o outro, sendo de $10 \%$ para o método tradicional e $5 \%$ para bootstrap, com 2819 replicações. O mesmo aconteceu com o fator potencial empreendedor, em que a diferença entre as médias dos grupos não foi significativa pelo método tradicional, mas pelo botstrap com 2819 replicações foi significativa ao nível de $10 \%$.

Isso significa que a intenção de empreender tanto de homens quanto de mulheres é igual. Dessa forma, o resultado do teste de hipótese para esse fator sugere que as pressões e padrões sociais, associados aos fatores culturais, políticos e econômicos, estão modificando as expectativas de papéis desempenhados por homens e mulheres na sociedade brasileira. Nesse contexto, as mulheres mostram-se mais dispostas a planejar suas atividades e a definir objetivos e tarefas, pois acreditam 
na importância do planejamento, como também revelam-se com mais capacidade de acompanhar a execução do que foi planejado, de checar o alcance dos resultados, de manter registros e utilizá-los no processo decisório e de realizar mudanças e adaptações sempre que necessário. Por fim, tendo em vista que o fator potencial empreendedor agrupa, além dos subfatores planejamento e controle, os subfatores oportunidade, eficiência, informações, metas, persuasão e rede de relações, e que, em todos esses, a média das mulheres foi maior que a dos homens, é esperado que, com tantas replicações, a composição desses subfatores apresente esse resultado. Como consequência, os dados indicam que as mulheres tendem a apresentar um potencial empreendedor maior do que o dos homens.

Com esses resultados, fica claro que a questão de gênero envolve uma construção social e um espaço simbólico produzido culturalmente. Ou seja, embora o indivíduo nasça com uma constituição biológica, é a natureza da sua relação com os outros que determina o aumento ou a diminuição da sua intenção de empreender e permite ou inibe a manifestação do seu potencial empreendedor (FERREIRA; NOGUEIRA, 2013). Os resultados dos estudos de Muller e Dato-on (2013), realizado nos Estados Unidos e na Espanha, e de Shinnar, Giacomin e Janssen (2012), realizado na China, Bélgica e Estados Unidos, validam empiricamente essa linha de pensamento. Em adição, os resultados dessa análise compactuam com os dados do Brasil, de 2014 (GEM, 2015a), sobre o número expressivo de empreendedoras femininas, e com a avaliação do empreendedorismo em nível global (GEM, 2015b).

Já em relação à variável religião, ressalta-se, com base nos dados da Tabela 10, que a média dos católicos para os subfatores oportunidade, persistência, eficiência, planejamento, metas, controle, persuasão e redes de relações e, por conseguinte do fator potencial empreendedor, foi maior que a média dos protestantes. Em contrapartida, a média dos 
protestantes foi maior para o fator intenção de empreender e para o subfator informação.

Os dados da análise das médias puramente sugerem que os católicos estão mais capazes de identificar oportunidades, de se manter firmes na busca de seus objetivos e metas, de realizar tarefas ao menor curso possível, de planejar suas atividades, de ter senso de direção, de monitorar a execução do que foi planejado, de liderar pessoas e de estabelecer contatos pessoais e de negócios. Por sua vez, os protestantes apresentam motivações e autoeficácia para possuir o próprio negócio, bem como mais disponibilidade para buscar informações que favoreçam o processo de empreender. Esses últimos dados seguem a mesma linha dos encontrados nos estudos qualitativos de Serafim, Martes e Rodriguez (2012), de Vieira e Jacinto (2013) e de Galdeano (2014), posto que, nesses três estudos, os autores chegar às mesmas considerações finais de que a prática religiosa protestante fomenta a autoestima e a intenção de empreender.

Entretanto, esses dados não se confirmam no teste de hipótese, pois a diferença de médias entre católicos e protestantes para nenhum desses fatores foi significativa ao nível máximo de 10\%, nos dois métodos estimados, tradicional e bootstrap com 2819 replicações. Portanto, com base nos resultados dessa última análise, infere-se que os indivíduos empreendedores estabelecem uma relação autônoma com sua religião. Isso, por conseguinte, denota que a relação entre religião e empreendedorismo não é puramente uma relação institucional, mas sim individualizada. Ou seja, o indivíduo empreendedor, como um agente diferenciado e autônomo, não é refém das instituições religiosas, pois se impulsiona por valores, motivações e características próprias (GRIEBEL; PARK; NEUBERT, 2014; VIEIRA; JACINTO, 2013). 
Tabela 9 - Teste de hipótese para a variável: gênero

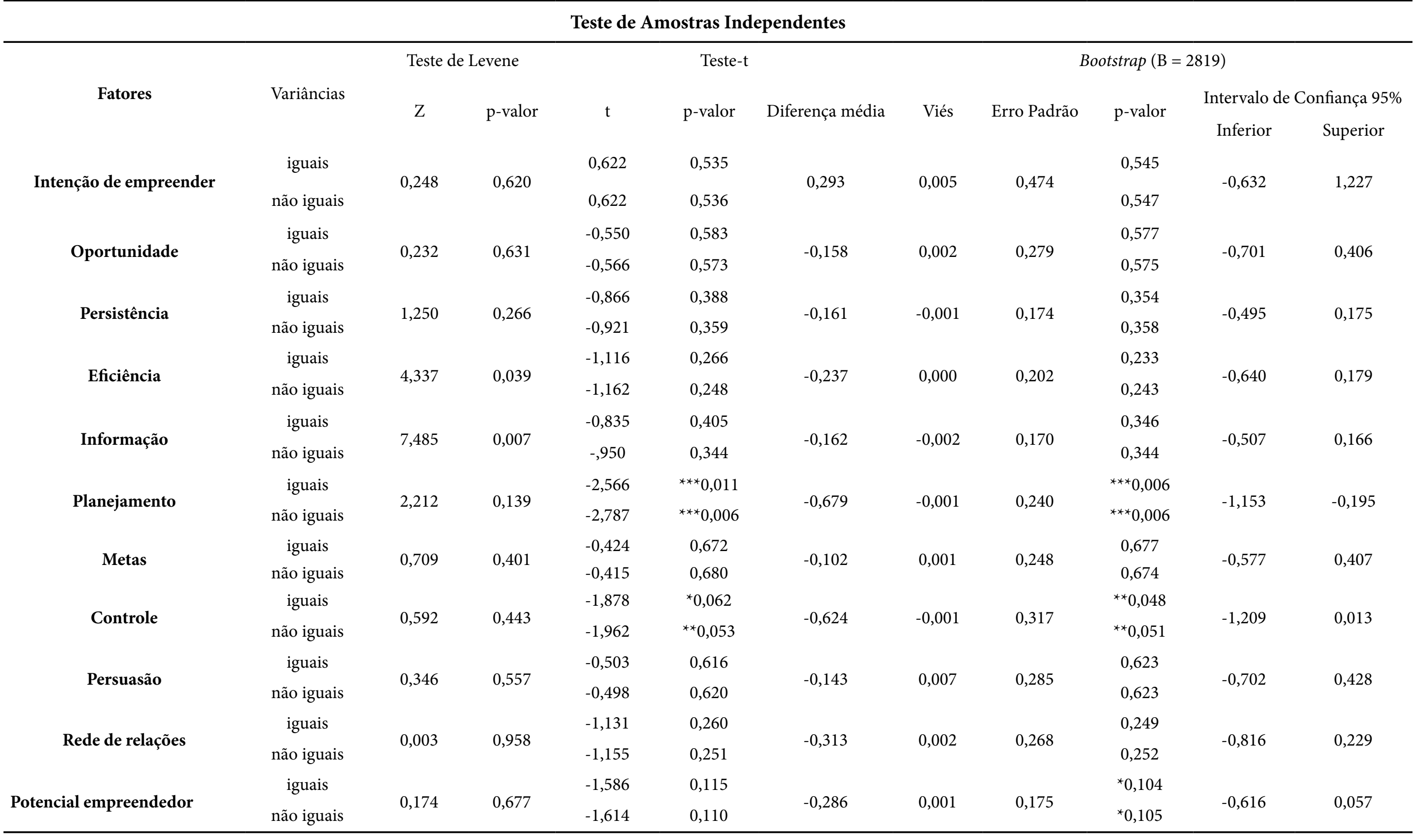

Nota: Os asteriscos $*$,***** correspondem aos respectivos níveis de significância $10 \%, 5 \%, 1 \%$.

Fonte: Dados da pesquisa (2013). 
Tabela 10 - Teste de hipótese para a variável: religião

\begin{tabular}{|c|c|c|c|c|c|c|c|c|c|c|c|}
\hline \multicolumn{12}{|c|}{ Teste de Amostra Independentes } \\
\hline \multirow{3}{*}{ Fatores } & \multirow{3}{*}{ Variâncias } & \multicolumn{2}{|c|}{ Teste de Levene } & \multicolumn{3}{|c|}{ Teste- $t$} & \multicolumn{5}{|c|}{ Bootstrap $(\mathrm{B}=2819)$} \\
\hline & & \multirow{2}{*}{$\mathrm{Z}$} & \multirow{2}{*}{ p-valor } & \multirow{2}{*}{$\mathrm{t}$} & \multirow{2}{*}{ p-valor } & \multirow{2}{*}{ Diferença média } & \multirow{2}{*}{ Viés } & \multirow{2}{*}{ Erro Padrão } & \multirow{2}{*}{$\mathrm{p}$-valor } & \multicolumn{2}{|c|}{ Intervalo de Confiança 95\% } \\
\hline & & & & & & & & & & Inferior & Superior \\
\hline Intenção de empreender & $\begin{array}{c}\text { iguais } \\
\text { não iguais }\end{array}$ & 0,073 & 0,788 & $\begin{array}{l}-0,216 \\
-0,216\end{array}$ & $\begin{array}{l}0,829 \\
0,830\end{array}$ & $-0,122$ & 0,008 & 0,566 & $\begin{array}{l}0,829 \\
0,831\end{array}$ & $-1,201$ & 1,036 \\
\hline Oportunidade & $\begin{array}{c}\text { iguais } \\
\text { não iguais }\end{array}$ & 0,226 & 0,636 & $\begin{array}{l}0,616 \\
0,598\end{array}$ & $\begin{array}{l}0,539 \\
0,553\end{array}$ & 0,216 & 0,012 & 0,367 & $\begin{array}{l}0,552 \\
0,553\end{array}$ & $-0,460$ & 0,972 \\
\hline Persistência & $\begin{array}{c}\text { iguais } \\
\text { não iguais }\end{array}$ & 0,209 & 0,648 & $\begin{array}{l}1,244 \\
1,195\end{array}$ & $\begin{array}{l}0,216 \\
0,239\end{array}$ & 0,249 & 0,008 & 0,211 & $\begin{array}{l}0,234 \\
0,244\end{array}$ & $-0,138$ & 0,676 \\
\hline Eficiência & $\begin{array}{c}\text { iguais } \\
\text { não iguais }\end{array}$ & 0,695 & 0,406 & $\begin{array}{l}0,683 \\
0,669\end{array}$ & $\begin{array}{l}0,496 \\
0,507\end{array}$ & 0,162 & 0,006 & 0,249 & $\begin{array}{l}0,523 \\
0,521\end{array}$ & $-0,305$ & 0,673 \\
\hline Informação & $\begin{array}{c}\text { iguais } \\
\text { não iguais }\end{array}$ & 0,200 & 0,656 & $\begin{array}{l}-0,089 \\
-0,087\end{array}$ & $\begin{array}{l}0,929 \\
0,931\end{array}$ & $-0,018$ & 0,010 & 0,210 & $\begin{array}{l}0,942 \\
0,943\end{array}$ & $-0,411$ & 0,393 \\
\hline Planejamento & $\begin{array}{c}\text { iguais } \\
\text { não iguais }\end{array}$ & 1,886 & 0,172 & $\begin{array}{l}0,858 \\
0,769\end{array}$ & $\begin{array}{l}0,393 \\
0,447\end{array}$ & 0,263 & 0,013 & 0,347 & $\begin{array}{l}0,456 \\
0,461\end{array}$ & $-0,376$ & 0,958 \\
\hline Metas & $\begin{array}{c}\text { iguais } \\
\text { não iguais }\end{array}$ & 0,293 & 0,590 & $\begin{array}{l}0,303 \\
0,304\end{array}$ & $\begin{array}{l}0,763 \\
0,762\end{array}$ & 0,086 & 0,010 & 0,285 & $\begin{array}{l}0,757 \\
0,757\end{array}$ & $-0,452$ & 0,679 \\
\hline Controle & $\begin{array}{c}\text { iguais } \\
\text { não iguais }\end{array}$ & 6,246 & 0,014 & $\begin{array}{l}1,142 \\
0,962\end{array}$ & $\begin{array}{l}0,256 \\
0,342\end{array}$ & 0,435 & 0,005 & 0,464 & $\begin{array}{l}0,354 \\
0,365\end{array}$ & $-0,419$ & 1,388 \\
\hline Persuasão & $\begin{array}{c}\text { iguais } \\
\text { não iguais }\end{array}$ & 0,030 & 0,863 & $\begin{array}{l}1,062 \\
1,076\end{array}$ & $\begin{array}{l}0,290 \\
0,287\end{array}$ & 0,351 & 0,003 & 0,331 & $\begin{array}{l}0,278 \\
0,286\end{array}$ & $-0,277$ & 1,037 \\
\hline Rede de relações & $\begin{array}{c}\text { iguais } \\
\text { não iguais }\end{array}$ & 0,056 & 0,814 & $\begin{array}{l}0,481 \\
0,455\end{array}$ & $\begin{array}{l}0,632 \\
0,651\end{array}$ & 0,160 & 0,006 & 0,348 & $\begin{array}{l}0,654 \\
0,657\end{array}$ & $-0,497$ & 0,849 \\
\hline Potencial empreendedor & $\begin{array}{c}\text { iguais } \\
\text { não iguais }\end{array}$ & 0,341 & 0,560 & $\begin{array}{l}1,012 \\
0,961\end{array}$ & $\begin{array}{l}0,314 \\
0,342\end{array}$ & 0,211 & 0,008 & 0,227 & $\begin{array}{l}0,354 \\
0,357\end{array}$ & $-0,209$ & 0,675 \\
\hline
\end{tabular}

Nota: Os asteriscos ${ }^{* * *},{ }^{* *}$ correspondem aos respectivos níveis de significância $10 \%, 5 \%, 1 \%$.

Fonte: Dados da pesquisa (2013). 


\subsection{Considerações finais}

Os dois testes t para amostras independentes empregados para atender ao objetivo de pesquisa trouxeram resultados inéditos para o campo de estudo sobre empreendedorismo, em níveis individual e institucional. Ao mensurar a intenção de empreender e o potencial empreendedor de jovens universitários na região Nordeste do Brasil, foi possível identificar diferenças e/ou similaridades entre indivíduos, de acordo com o seu gênero e a sua orientação religiosa e deduzir se essas diferenças e similaridades são individuais e/ou institucionais. Isso se deve, em parte, à utilização de uma escala que mensura, ao mesmo tempo, um fator mais dependente das influências sociais e institucionais e outro fator mais relacionado às características individuais (SANTOS, 2008).

O primeiro teste, utilizado para contrastar a diferença de médias na intenção de empreender e no potencial empreendedor entre pessoas do sexo masculino e pessoas do sexo feminino, revela que a relação entre gênero e empreendedorismo é uma construção social e cultural, posto que os dados mostram que não há diferenças significativas no desejo de empreender, de ter o seu próprio negócio, entre os grupos. Isso sugere que as expectativas de papéis feminino e masculino, no que diz respeito à ação empreendedora, vêm se igualando, devido às transformações sociais, culturais, políticas e econômicas vivenciadas na sociedade contemporânea, no caso específico deste estudo, no contexto brasileiro e nordestino. No entanto, há diferenças significativas na média entre os grupos em relação ao fator que agrupa as características individuais para empreender. Essas diferenças são maiores para as mulheres, que apresentam um potencial empreendedor maior que o dos homens, com ênfase para a capacidade de planejar e controlar atividades. Dessa forma, a primeira hipótese foi parcialmente confirmada.

O segundo teste, utilizado para contrastar a diferença de médias na intenção de empreender e no potencial empreendedor entre adeptos 
do Catolicismo e adeptos do Protestantismo, indica que, mais do que institucional, a relação entre religião e empreendedorismo é uma relação autônoma e individualizada, tendo em vista que a diferença de médias entre os grupos não foi significativa para nenhum dos fatores ou subfatores analisados. Nesse caso, a segunda hipótese não foi confirmada.

Os resultados desses testes, embora elucidativos, dão margens a outros questionamentos de pesquisa. A amostra utilizada neste estudo limitou-se a um público específico, de jovens universitários, a maioria com idade entre 18 a 24 anos, e do mesmo curso. O curso de bacharelado em Ciências e Tecnologia na instituição pesquisada serve de ingresso para cursos de engenharias, como Civil, Mecânica, Química e outros. Um estudo com uma amostra que apresente uma média de idade mais avançada ou com integrantes de cursos de ciências sociais, humanas ou da área de saúde podem revelar resultados diferentes dos encontrados neste estudo.

Por não se caracterizar como objetivo deste estudo, aspectos importantes foram negligenciados. A investigação de tais aspectos como: estado civil, filhos, ocupação, influência paterna e materna e grau de envolvimento (participação e frequência à igreja) religioso podem esclarecer outras questões relacionadas à intenção de empreender e ao potencial empreendedor. 


\section{REFERÊNCIAS}

ALMEIDA, D; SANTOS, M. A. R. dos; COSTA, A. F. B. Aplicação do coeficiente alfa de Cronbach nos resultados de um questionário para avaliação de desempenho da saúde pública. In: ENCONTRO NACIONAL DE ENGENHARIA DE PRODUÇÃO, 30, 2010, São Carlos. Anais... São Carlos: ABEPRO, 2010.

AUDRETSCH, D. B; BÖNTE, W; TAMVADA, J. P. Religion and entrepreneurship. Position Paper. Max-Planck Institute of Economics, Entrepreneurship, Growth and Public Policy Group, Kahlaische Strasse 10, Jena, Germany. 2007.27p.

AUDRETSCH, D. B; BÖNTE, W; TAMVADA, J. P. Religion, social class, and entrepreneurial choice. Journal of Business Venturing, v. 28, n. 1, p. 774-789, 2013.

BARON, R. A; SHANE, S. A. Empreendedorismo: uma visão de processo. São Paulo: Thomson Learning, 2007.

CAMERON, A. C; TRIVEDI, P. K. Microeconometrics: methods and applications. New York: Cambridge University Press, 2005.

CARSWELL, P; ROLLAND, D. Religion and entrepreneurship in New Zeland. Journal Enterprising Communities: People and Places in the Global Economy, v. 1, n. 2 p. 162 - 174, 2007.

FERREIRA, J. M; NOGUEIRA, E. E. S. Mulheres e suas histórias: razão, sensibilidade e subjetividade no empreendedorismo feminino. RAC - Revista de Administração Contemporânea, v. 17, n. 4, p. 398-417, 2013. 
FISCHER, E. M; REUBER, A. R; DYKE, L. S. A theoretical overview and extension of research on sex, gender, and entrepreneurship. Journal of Business Venturing, v. 8, n. 1, p. 151-168, 1993.

FREITAS, A. L. P.; RODRIGUES, S. G.. A avaliação da confiabilidade de questionários: uma análise utilizando o coeficiente alfa de Cronbach. In: SIMPEP - SIMPÓSIO DE ENGENHARIA DE PRODUÇÃO, 12, 2005, Bauru (SP). Anais... Bauru (SP): UNESP, 2005. Sem paginação

FOX, J. Applied regression analysis and generalized linear models. 2. ed. Califórnia: SAGE Publications, 2008.

GALDEANO, A. P. Salmo 127, versículo 1: ativismo religioso e ordenamentos da segurança em uma periferia de São Paulo. Religião e Sociedade, v. 34, n. 1, p. 38-60, 2014.

GRANOVETTER, M. Ação econômica e estrutura social: o problema da imersão. READ - Revista de Administração de Empresas - Eletrônica, v. 6, n. 1, 2007. Disponível em: <http://rae.fgv.br/sites/rae.fgv.br/files/artigos/10.1590_S167656482007000100010.pdf>. Acesso em: 27 jul. 2015.

GLOBAL ENTREPRENEURSHIP MONITOR (GEM).

Empreendedorismo no Brasil: Relatório Executivo - 2014, São Paulo: Instituto Brasileiro da Qualidade e Produtividade (IBQP), 2015a. 18p.

GLOBAL ENTREPRENEURSHIP MONITOR (GEM). 2014 Global Report. London: Global Entrepreneurship Research Association (GERA), 2015b. 116p.

GRIEBEL, J. M; PARK, J. Z; NEUBERT, M. J. Faith and work: an exploratory study of religious entrepreneurs. Religions, v. 5, n. 1, p. 780-800, 2014. 
HOOGENDOORN, B; RIETVELD, C. A; VAN STEL, A. Exploring the relation between religion and business ownership at country level. Position Paper. Department of Applied Economics, Erasmus School of Economics, Erasmus University Rotterdam, Rotterdam, The Netherlands, 2014. 20p.

INÁCIO JÚNIOR, E. et al. From 1980 to 2010: an overview about the Brazilian scientific production in entrepreneurship. International Journal of Entrepreneurship, v. 18, n. 1, p. 129-141, 2014.

JONATHAN, E. G. Mulheres empreendedoras: o desafio da escolha do empreendedorismo. Psicologia Clínica, v. 23, n. 1, p. 65-85, 2011.

MARTES, A. C. B. Weber e Schumpeter: a ação econômica do empreendedor. Revista de Economia Política, v. 30, n. 2, p. 254270, 2010.

MARTES, A. C. B; RODRIGUEZ, C. L. Afiliação religiosa e empreendedorismo étnico: o caso dos brasileiros nos Estados Unidos. RAC - Revista de Administração Contemporânea, v. 8, n. 3, p. 117-140, 2004.

MERINO; A. P; DÍAZ, M. A. R. Análisis de datos con SPSS 13 base. Madrid: McGraw- Hill, 2005.

MORAIS, A. R. A relação entre intenção e potencial de empreender e características demográficas. 2013. 48 f. Trabalho de Conclusão de Curso (Bacharelado em Ciência e Tecnologia)-. Universidade Federal do Semiárido, Mossoró, 2013.

MULLER, S. L; DATO-ON, M. C. A cross cultural study of genderrole orientation and entrepreneurial self-efficacy. International Entrepeneurship Management Journal, v. 9, n. 1, p. 1-20, 2013. 
PEÑALOZA, V; DIÓGENES, C. G; SOUSA, S. J. A. Escolha profissional no curso de administração: tendências empreendedoras e gênero. RAM - Revista de Administração Mackenzie, v. 9, n. 8, edição especial, p. 151-167, 2008.

POWELL, G. N; EDDLESTON, K. A. Linking family-to-business enrichment and support to entrepreneurial success: Do female and male entrepreneurs experience different outcomes? Journal of Business Venturing, v. 28, n. 1, p. 261-280, 2013.

ROCHA, E. L. de C; FREITAS, A. A. F. Avaliação do ensino de empreendedorismo entre estudantes universitários por meio do perfil empreendedor. RAC - Revista de Administração Contemporânea, v. 18, n. 4, p. 465-486, 2014.

SABAH, S; CARSRUD, A. L; KOCAK, A. The impact of cultural openness, religion, and nationalism on entrepreneurial intensity: six prototypical cases of Turkish family firms. Journal of Small Business Management, v. 52, n. 2, p. 306-324, 2014.

SANTOS, S. C; CAETANO, A; CURRAL, L. Atitude dos estudantes universitários face ao empreendedorismo: como identificar o potencial empreendedor? Revista Portuguesa e Brasileira de Gestão, v. 9. n. 4, p. 2-14, 2010.

SANTOS, P. C. F. Uma escala para identificar potencial empreendedor. 2008. 366 f. Tese (Doutorado em Engenharia de Produção)-Universidade Federal de Santa Catarina, Florianópolis, 2008.

SERAFIM. M. C; FEUERSCHÜTTE, S. G. Movido pelo transcendente: a religiosidade como estímulo ao "espírito empreendedor". Cadernos EBAPE.BR, v. 13, n. 1, p. 166-183, 2015. Disponível em: <http://www.scielo.br/pdf/cebape/v13n1/1679-3951cebape-13-01-00165.pdf $>$. Acesso em: 06 maio 2015. 
SERAFIM. M. C. Economia de comunhão como expressão de uma economia plural de origem religiosa. Revista de Economia de Comunhão, v. 1, n. 3, p. 76-99, 2013.

SERAFIM. M. C; MARTES, A. C. B; RODRIGUEZ, C. L.

"Segurando na mão de Deus": organizações religiosas e apoio ao empreendedorismo. RAE - Revista de Administração de Empresas, v. 52, n. 2, p. 217-231, 2012.

SHINNAR, R. S; GIACOMIN, O; JANSSEN, F. Entrepreneurial perceptions and intentions: the role of gender and culture.

Entrepreneurship: Theory and Practice, v. 36, n. 3, p. 465-493, 2012.

SILVER, D; O'NEILL, K. The significance of religious imagery in the Philosophy of Money: Money and the transcendent character of life.

European Journal of Social Theory, v. 17, n. 4, p. 389-406, 2014.

VALE, G. M. V; SERAFIM, A. C. F; TEODÓSIO, A. dos S. de S. Gênero, imersão e empreendedorismo: sexo frágil, laços fortes? RAC - Revista de Administração Contemporânea, v. 15, n. 4, p. 631-649, 2011.

VAN DER LOOS, M. J. H. M. et al. Serum testosterone levels in males are not associated with entrepreneurial behavior in two independent observational studies. Physiology \& Behavior, v. 119, n. 1, p. 110-114, 2013.

VIEIRA, J. P. V. S; JACINTO, P. de A. Religião e empreendedorismo no Brasil: uma análise utilizando modelos de escolha ocupacional. In: ENCONTRO DE ECONOMIA DA REGIÃO SUL, 16, 2013, Curitiba, Anais... Curitiba: ANPEC SUL, 2013.

WEBER, M. A ética protestante e o "espirito" do capitalismo. São Paulo: Companhia das Letras, 2004. 